\title{
THE COLONIAL MICROBIOLOGICAL RESEARCH INSTITUTE, TRINIDAD
}

$\mathrm{T}$

HE ceremony of the opening of the Colonial Microbiological Research Institute in Port-ofSpain, Trinidad, British West Indies, was performed on July 5 by Lord Hankey, in the presence of a distinguished gathering including the Governor of Trinidad and Tobago, Sir John Shaw ; the chairman of the Standing Closer Relations Committee, Sir Hubert Rance; Prof. J. L. Simonsen, director of research of the Colonial Products Research Council; the principal of the University College, Jamaica, Dr. Taylor; the acting principal of the Imperial College of Tropical Agriculture, Trinidad, Dr. Shepherd; and delegates from other Caribbean countries, from the United States, Mexico, Venezuela, Honduras, etc.

Introducing Lord Hankey, the Governor expressed his satisfaction at the presence of Lord Hankey and of so many distinguished delegates; on behalf of the peoples of Trinidad and Tobago he thanked Lord Hankey for having chosen Trinidad for this undertaking, which he understood was to serve as a research centre for theoretical and applied microbiology for the benefit of the Colonial Empire as a whole.

In a message read by Lord Hankey, Sir Robert Robinson, president of the Royal Society, conveyed the following greetings from the Royal Society: "It is impossible to visit any tropical or sub-tropical country without becoming more and more insistently aware of the importance of general microbiological research. In the field of the pathogenic organisms this need has long been recognized, and to some extent satisfied, but the importance of the wider aspect has not been equally well understood. Entirely inadequate provision has been made for such investigations whether from the point of view of pure biology, biochemistry, hygiene and medicine, or of industry. When Dr. Simonsen and I visited Trinidad in 1944, the need for extended microbiological research was obvious to us as a special instance of the general thesis. It was clear, too, that the facilities that could be made available, the side-contacts, and the general conditions were favourable for the development contemplated. Not only the health of the community in the physical sense, but also in the economic sphere, was seen to be tied up with microbiology in its wider implications.

"On return to England, we found as a most fortunate and compelling circumstance that it might be possible to persuade Dr. Thaysen to undertake the organisation and first Directorship of a projected Institute for Microbiological Research. That was decisive and further steps taken are well known to you all. It is with real satisfaction that I send this message of felicitation to an Institute which I am sure is destined, not only to play an important part in the development of Trinidad and the Caribbean, but also to give an example to the rest of the world. It will surely make a significant contribution to science and we hope also to human happiness and prosperity."

In his address, Lord Hankey gave a brief review of British Colonial policy and organisation in scientific research and development in which the Institute is a link, and he sketched the history of the Institute's conception.

Amplifying Sir Robert Robinson's remarks, Lord Hankey asked : "Our aspirations! What are they ? I dare not pitch them too high, or we may disappoint you. I must not pitch them too low, because, on a long view, they have no ceiling any more than has the blue firmament above Trinidad. But our first aspiration must be pure research; that wresting from Nature of her secrets; that process of getting to the bottom of things from which great results follow. Think of the pioneer work of Newton, of Faraday, of Herschel, of Pasteur, of Rutherford, and hundreds of others from which have been produced the marvels of modern science. Apply that thought to microbiology and you get some idea of our fundamental aims and ambitions for the microbiological institute.

"But we shall not limit ourselves to pure science. We shall continue, as hitherto, to exploit to the utmost the application of research for the benefit of mankind.

"It will interest you to know that, as the result of a recommendation by the British Commonwealth

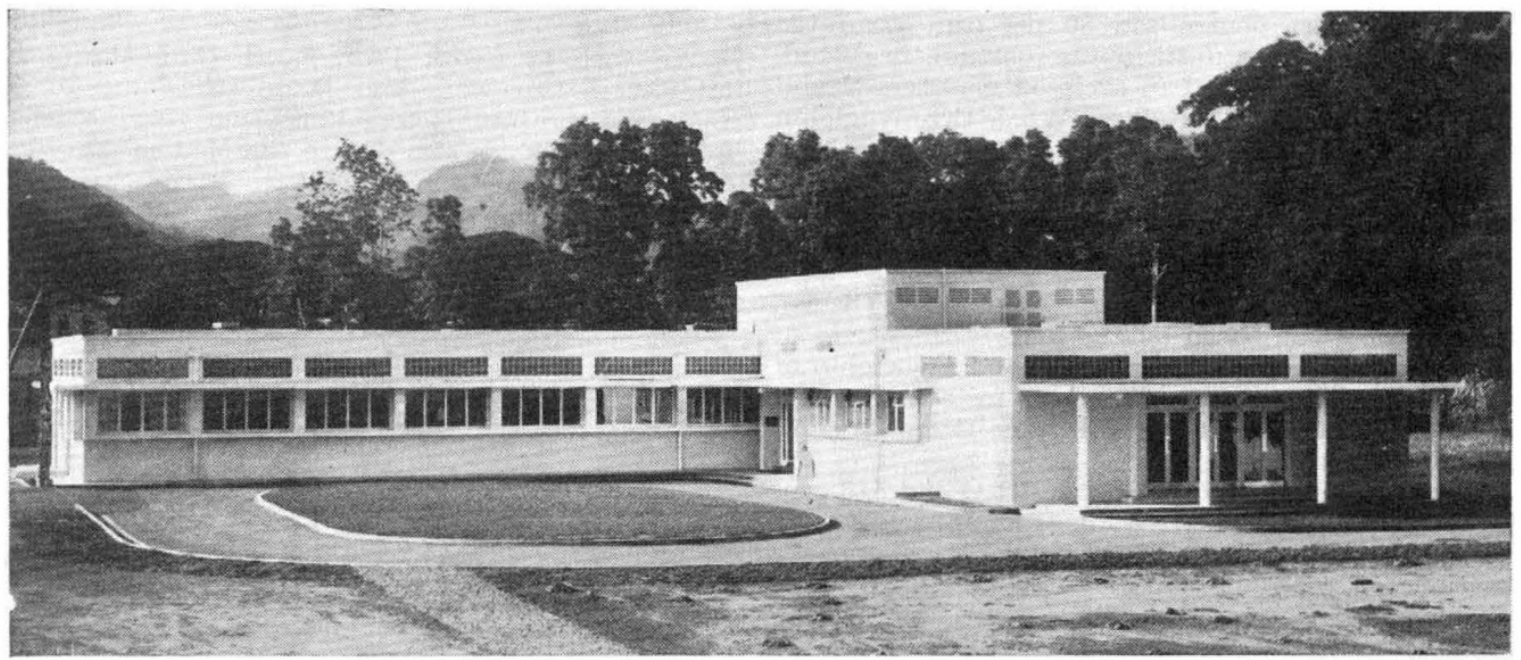

The Colonial Microbiological Research Institute 
Scientific Official Conference in 1946, the Microbiological Institute in Trinidad has become an official centre for the British Commonwealth for Culture Collections of Micro-organisms, where types of micro-organisms will be carefully preserved. That is essential if full advantage is to be taken of research in microbiology.

"I could give many further illustrations of what we have accomplished in our early, pioneer years, but I have said enough to give some impression of the kind of benefits we hope to derive from the pursuit of microbiology in this Institute; but in saying that, I must again emphasize that pure research must come first and that any deviation from that aim in pursuit of quick results might be calamitous."

Lord Hankey then went on to ask why Trinidad had been chosen for this important work. To begin with, he said, it was essential that the work undertaken in a new centre being intended mainly for the good of the tropical Empire should be undertaken within the tropics. "We were greatly influenced also," he continued, "by previous experience of the danger of placing such an Institute in isolation. A.part from the Caribbean Research Council, Trinidad already houses the famous Imperial College of Tropical Agriculture with its valuable library, and it seemed to us that to place the Institute within easy reach of the College should be of material benefit to both, owing to the close association with other scientists that each would enjoy. In this connexion it is very interesting that Dr. L. F. Wiggins, who has been prominent in assisting Sir Norman Haworth on the important work at Birmingham University on starch and sugar to which I have already referred, has recently been appointed by the West Indies Sugar Association as head of the new Department of Sugar Technology at the College. This should give a splendid start to the development of this branch of the College which was another of the suggestions made by Sir Robert Robinson and Prof. Simonsen.

"We had in mind also the opportunities that the Institute might afford for the important study of soil microbiology, and we did not overlook the prospects of invaluable contacts with the scientists of the Trinidad Government and of the refineries, oil companies and other industrial concerns in the island, as well as its associations, societies, and institutes. In particular we look forward to a close link with the University College of the West Indies.

"But to these more or less official reasons for the selection of Trinidad I would add one more, which makes a special appeal to me, as a layman, and is expressed in language more eloquent and more imaginative than I can command in the following passage from Charles Kingsley's 'At Last', chapter 14, entitled 'The High Woods', which was inspired by his observation of the Trinidad forest, while visiting the island in the last century : 'The eye is not filled with seeing, or the ear with hearing; and never would be, did you roam these forests for a hundred years. How many years would you need merely to examine and discriminate the different species? And when you have done that, how many more to learn their virtues, properties, uses ? By what miracle they are compacted out of light, air and water, each after its kind? How, again, these kinds begin to be and what they were like at first? Whether these crowded, struggling, competing shapes are stable or variable? Whether or not they are varying still ? Whether even now, as we sit here, the Great
God may not be creating, slowly, but surely, new forms of beauty around us.' To sum up-in the words of Lucretius-'Felix qui potuit rerum cognoscere causas' (Happy is he who can know the causes of things. Lucretius, 'De Rerum Naturæ')."

After luncheon the company proceeded to the grounds of the Institute and here Lord Hankey unveiled a plaque with the name of the Institute engraved upon it, and opened the main entrance door with a key made of West Indian gold and presented to him by the architects who designed the buildings, Messrs. Watkins and Partners, of Bristol and Port of Spain. At the suggestion of the Director, Lord Hankey graciously consented to have his name associated with the culture collection maintained at the Institute as a link with Commonwealth culture collections of micro-organisms, and agreed that this culture collection in future should be known as "The Hankey Culture Collection" instead of the "Colonial Culture Collection".

A description of the Institute has already been given in Nature of July $3, \mathrm{p} .14$.

Following the official opening, two morning sessions on July 6 and 7 were held in the library of the Institute. At the first of these Lord Hankey took the chair, and at the second, Prof. J. L. Simonsen. Many delegates and others read papers at these meetings, which were largely attended.

It is hoped, in due course, to compile an abbreviated account of the subjects dealt with in these discussions, and to issue them as a commemorative publication.

J. L. SIMONSEN

\section{SOUND TRANSMISSION AND NOISE}

A VERY successful symposium on sound transmission and noise was held during July 14-16 by the Acoustics Group of the Physical Society, with the kind co-operation of the Royal Institute of British Architects, in the Jarvis Hall of the latter, at Portland Place, London. The proceedings were opened by Mr. H. L. Kirke, chairman of the Group, and overseas visitors were present from the United States, France, Denmark, Holland, Sweden, Switzerland, Italy and Germany.

The opening session was devoted to problems of sound transmission. In the first paper, Dr. L. L. Beranek, of the Massachusetts Institute of Technology, described investigations he has been carrying out into the determination of the attenuation of single and multiple panels. To avoid the expense of the usual two-room method, he has developed a model test using panels 18 in. square giving results which agree well with full-scale tests and with theory. He has applied the theory to seven kinds of structures and has deduced charts which enable the attenuation, for partitions of known dimensions, mass and porosity, to be readily determined. Similar work in Great Britain at the National Physical Laboratory was described by Dr. G. H. Aston. He has not found any marked effect with size in the attenuation of glass windows, but there is an upper limit to the mass which it is worth while using set at $24 \mathrm{oz}$. glass by the compliance of the framing. With double windows there is an increase in attenuation with spacing even up to $7 \mathrm{in}$. at low frequencies, but $4 \mathrm{in}$. is sufficient at high frequencies. His work on plaster walls has 